\title{
Impact of COVID-19 on Dental Education
}

\author{
Ananya Madiyal ${ }^{1}$ Supriya Bhat ${ }^{1} \quad$ G. Subhas Babu ${ }^{1} \quad$ Sonika Achalli ${ }^{1}$
}

${ }^{1}$ Department of Oral Medicine and Radiology, A.B. Shetty Memorial Institute of Dental Sciences, Mangalore, Karnataka, India
Address for correspondence Supriya Bhat, MDS, Department of Oral Medicine and Radiology, A.B. Shetty Memorial Institute of Dental Sciences, Deralakatte, Mangalore 575018, Karnataka, India (e-mail: dr.supriyabhat@gmail.com).

\begin{abstract}
Keywords

- COVID-19

- dental

- education

- e-learning

- remote learning

With the closure of educational institutions across the world, didactic education has come to a stop from the level of primary education up to the level of professional training. Due to the discovery of a high viral load in saliva, dental schools have been considered as a hub of potential disease transmission. Students have reported anxiety over their safety, availability of learning resources, and retaining their efficiency of patient care after dental schools open. Administrators and educators are scrambling to ensure an effective learning experience while retaining the flexibility to adapt to new challenges. Ensuring a uniform grading system for year-end examinations, exit, and entrance examinations will help young professionals retain their career momentum. Problem-based learning, case-based and team-based learning, objective structured clinical examinations, and flipped classrooms are some of the methods that can be used to continue e-learning among dental students while we learn to live in this "new normal" situation.
\end{abstract}

\section{Introduction}

The SARS COVID-19 virus is hypothesized to be a zoonotic infection that continues to undergo human-to-human transmission globally. ${ }^{1}$ Although humans present with relatively mild symptoms, it has proven to be fatal in a considerable number of people with comorbidities, the patients succumbing to severe respiratory illness or other complications. ${ }^{2}$ At the time of writing this review, there is no proven cure for the disease, nor are there any vaccinations to prevent it from occurring. This, combined with a lack of innate immunity against the virus, has led to widespread disease and has challenged the health care system like never before. ${ }^{3}$

When the World Health Organization assessed health care education in 1972, it found that the education system was closely integrated with the health care system. ${ }^{4}$ The concern over a culture of commercialism of education has given rise to proposals to have a "patient-centric" education system rather than a "profit-centric" model. As dental educators, it is important to design a curriculum that is competency-based, blends dental education with the overall health care goals of the country while at the same time reforms the learning environment to develop well-rounded dental professionals. The globalization of dental education through the use of technology can eliminate the difference in the quality of dental education, dental professionals, and dental educators across the world. ${ }^{5}$

Cessation of face-to-face didactic education system throughout the world has seen a disruption in the education of students from the primary level up to the level of professional training. While most institutions are trying to cope with newer methods of teaching and learning, a lack of precedent in these types of situations has put an additional burden on institutions as well as the students. With social distancing becoming the "new normal," providing an authentic patient care experience for medical and dental students is an increasing concern. published online

January 21, 2021
DOI https://doi.org/

$10.1055 / \mathrm{s}-0040-1722792$ ISSN 2582-4287. (c) 2021. Nitte (Deemed to be University).

This is an open access article published by Thieme under the terms of the Creative Commons Attribution-NonDerivative-NonCommercial-License, permitting copying and reproduction so long as the original work is given appropriate credit. Contents may not be used for commercial purposes, or adapted, remixed, transformed or built upon. (https://creativecommons.org/licenses/by-nc-nd/4.0/).

Thieme Medical and Scientific Publishers Pvt. Ltd. A-12, 2nd Floor, Sector 2, Noida-201301 UP, India 


\section{Impact on Education}

It was observed that students touch their faces on an average of 23 times every hour, the greatest contact being the skin and lowest being the eyes. ${ }^{6}$ This poses both practical and logistical challenges of students being unsuspecting, asymptomatic carriers of infection. Considering the rapid nature of the spread of the disease, most countries worldwide have stopped face-to-face lectures at their educational institutions to minimize transmission. However, discussions for reopening of institutions are now ongoing. With educators scrambling to improve the efficacy of their online teaching, there is still a learning curve to overcome. A plan must be made to ensure appropriate distance-learning etiquette but remain flexible enough to adapt to new challenges as they approach. The success of e-learning depends on the attitude and interaction of both the students and the faculty. The faculty should receive adequate training in dispensing of online teaching methods, and students must be educated on maximizing the advantage of all e-learning resources. ${ }^{7}$ The success of online modes of teaching and learning may be assessed based on the ease of access to both the learners and the educators, provision for interaction between the two, and their overall satisfaction after using the online learning tools. The willingness of teachers to share content online, the ability of students to inculcate the knowledge shared online, and the quality of online content play a major role in the success of online education. Various cultural, economic, and political factors also act as determining aspects in the ease of transition from the traditional method of learning to the online method. ${ }^{8}$

Synchronous teaching with peer interactions and asynchronous teaching moderated by a faculty must both be incorporated to achieve a well-rounded educational experience. Flipped classroom and Problem-Based Learning (PBL) can be utilized to ensure that the students have understood what was taught in the previous classes. ${ }^{9}$ With the validity of exam scores in an online platform being questioned, it might be prudent to shift to a "pass/fail" grading system until a more precise method is developed.

\section{Challenges in Dental Education}

Dental education throughout the world follows one of the two models-the odontology model followed in some parts of Europe, North and South Americas, Japan, India, and Australia or the stomatology model followed in other parts of Europe and China. The odontology model recognizes dental education as a separate entity from medical education while the stomatology model dictates that dental education is a specialty of medical education. ${ }^{5}$ Variations between countries in matters of education matrix and practice regulations make it difficult to set a global model for competency in dental education.

Dentists have been classified as a "very high-risk" group due to their inevitable contact with body fluids and aerosol during dental procedures. ${ }^{7}$ Large droplets contribute to contamination of nearby surfaces while small droplets cause transmission over a large distance. ${ }^{10}$ Owing to the high viral load in saliva, dental schools can potentially be a "hub" for transmission of the disease between patients, students, and teachers who share the same space. ${ }^{3}$ Dental educators and administrators must make a timely leap toward computer-based teaching methods to ensure the safety of their patients, students, and employees as well as continuity of education. ${ }^{7}$ Knowledge fragmentation due to the inability to integrate theoretical and preclinical laboratory teaching to patient care is routinely reported with traditional teaching methods. Interactive multimedia teaching may provide better intellectual stimulation owing to immediate feedback. ${ }^{5}$

Most dental teaching hospitals had earlier restricted their clinical activities to only dental emergencies but are now preparing for nonemergent cases. With teaching moved to an online space, students have reported anxiety regarding completion of clinical requirements, patient care, safety after the resumption of classes, and their impending graduation. ${ }^{7}$ Recent graduates report a loss in momentum that they might have been able to build in the early stages of their profession. ${ }^{11}$ Students must be supported with periodic communication with their mentors and the availability of counseling sessions to cope with this unique situation.

The biggest challenge for students is the unavailability of direct patient care education, while the biggest challenge for educators is to find means to keep the students engaged and motivated during virtual class sessions. Dental simulators are not a routine part of dental education in most dental schools. But switching to simulation teaching aides may enhance the students' confidence with regard to patient care after they return to their learning environment. ${ }^{5}$ Virtual reality and haptic technology are not readily available; neither are they portable to be utilized during this situation. ${ }^{7}$ Students, especially those engaged in their specialization training and those pursuing their PhD, miss the opportunity of attending conferences and symposiums that are important for the exchange of ideas. They also miss the prospect of learning the art of presenting their findings to their superiors and peers. Participation in online conferences and symposia is one way to navigate this situation. Students can also be encouraged to utilize this time to write and publish research papers with the help of their mentors. ${ }^{12}$ Another challenge is the conduction of end-of-the-year examinations, licensing exams, and entrance exams for admission into Masters courses and specialty training.

\section{Online Mode of Education and Assessment}

Distance learning must not only strive to reduce physical and temporal distance but also enable the students to acquire knowledge, while at the same time, respect their learning ability and discover their personal learning preferences. ${ }^{13}$ Online learning provides the benefit of allowing students to learn at their pace at a place that is most comfortable to them. It saves time and is usually less expensive than enrolling in a physical course. It also facilitates participation from individuals across a wide range of learning abilities. From an administrative point of view, it overcomes the hassle of faculty shortage, 
improves working hours of the educators, and shifts from a passive teacher-centric method of education to a more interactive learner-centric model. ${ }^{14}$

Group discussions, presentation of cases of clinical importance, PBL, flipped classroom, case-based and team-based learning, as well as timed quizzes, may be used to assess the impact of e-learning methods. ${ }^{12,15}$ Objective structured clinical examination, along with peer-reviewed assessments of their previous clinical work via teleconferences or webinars in the presence of a team of supervisors can play a role in final certification. ${ }^{7,12}$ Multiple in-course tests combined with graded assignments and a final exam will help break down the course into sizable bits that the learner can progress through. It also gives a sense of accomplishment to the student. Graduations may be delayed indefinitely or held online. ${ }^{7}$

Virtual learning has the added benefit of allowing the learner to progress at their own pace in a subject that matters the most to them. This will promote a more motivated student pool that will strive to gain expertise in subjects that interest them rather than participate in rote learning. Distance education allows the learner to participate in independent learning according to their spaciotemporal learning ability and facilitates collaborative learning. ${ }^{16}$

Taking tests and uploading graded assignments through a learning management system, participating in virtual classrooms, real-time feedback via social media with content-specific hashtags, or a classroom-based voting system that allows answering "yes or no" type questions immediately when the educator asks them will provide the social interaction that students miss while participating in online learning. ${ }^{8}$ The course director, teaching assistant, or the course facilitator can use this data to improve future classes and formulate a curriculum that is helpful to both the learners as well as the educators. The use of social networking helps the educator in creating interest among the learners before they start their course. It also helps the students interact with their peers, discuss ideas, help each other with projects, and improve the overall quality of their education. Tele-education and tele-assistance to help the students breakdown their projects and answer any questions that they may have during the course will decrease their apprehension while moving from the traditional method of learning to the online sphere. ${ }^{16}$

The major advantages of online learning are that it focuses on the needs of the learner, creates a learning space that is free of constraints of time and logistics, and allows the learner to manage their time and resources effectively. It also provides an interactive and collaborative teaching and learning environment where learners can progress through the course in their own stride. However, each learning method comes with its own disadvantages. Online learning hinders socialization and personal interaction between the learners and the teacher. Effective switch-over to virtual learning requires adequate access to hardware and software tools. Maintaining the quality of multimedia uploaded, ease of navigation, and speed of Internet connectivity may be difficult to achieve in places where digital services are not fully incorporated into peoples' everyday lives. ${ }^{14}$ Ensuring that every student has the necessary infrastructure needed to continue their education uninterruptedly might not be feasible in developing countries, especially in houses where multiple learners necessitate the availability of multiple devices and adequate Internet data for all of them. To overcome these disadvantages, an alternative learning method that blends the advantages of traditional teaching as well as online teaching can be employed in the future. This will help reduce educational costs but also provide increased access and equal opportunities to all learners. Such an approach will meet the needs of students with divergent learning abilities and allow learners to operate smoothly in any learning environment and motivate them to become actively involved in the content. ${ }^{17}$

Research has showed that transition to online mode of teaching requires increased time and resources to be invested by the institution to develop online study material as well as technical support. From an administrative point of view, it is carries a risk of shifting education from analysis and discussion to marketing and advertisement. A fragmented sense of time, decrease in attention span, and a feeling of estrangement from the community has been reported by learners who exclusively use virtual learning. ${ }^{18}$ It is important to find sustainable approaches to the new teaching methods as well as find new ways of interaction and exchange of knowledge while keeping in mind moral and ethical issues.

\section{Dental Clinical Training}

The nature of dental education is such that there is an emphasis in the need for the syllabus to be periodically updated, pragmatic, and evidence based. Virtual learning develops a student's ability for self-directed learning and ensures the habit of lifelong learning. Methods such a case-based and team-based learning as well as PBL develops the students' critical thinking ability that is needed in today's world of dentistry. ${ }^{19}$ In the authors' institution, self-directed learning modules and lecture series were developed during the time of pandemic that demonstrated clinical skills that were customized for the students based on their year of dental education. The students were tested on their retention of these skills so as to be prepared to implement them upon return to the dental school.

Student appraisals regarding the quality of online learning materials and methods adopted by the institutions as well as evaluation of their attitude toward the same will provide an accurate measure of the success of online learning. With the uncertainty of education methods that can be employed in the future, it is important to update the students' theoretical and practical skills to set up a secure foundation for a long-term clinical practice. Dental schools must offer a range of courses for all academic and clinical skill levels. A globally accepted method of professional accreditation that takes into account the students' diagnostic acumen, critical thinking, and procedural skills may be the way forward.

\section{Conclusion}

Students must be considered as a population with a substantial number of potential contacts. Dental schools must 
consider the possible use of online teaching methods to train their students theoretically and provide basic practical knowledge about various procedures that they will encounter after schools are open. While dental procedures require practice before the student is capable of dealing with patients, these measures will ensure that they are confident of retaining their knowledge and skills while being confined at home. But institutions must also take into account the various loopholes and problems associated with such teaching and learning methods and try to minimize them wherever possible. Dental institutions must re-evaluate and reprioritize their strategies of patient care and student welfare during these trying times.

\section{Conflict of Interest}

None declared.

\section{References}

1 Mohammadi M, Meskini M, do Nascimento Pinto AL. 2019 novel coronavirus (COVID-19) overview. Z Gesundh wiss 2020;19:1-9

2 Phan T. Novel coronavirus: from discovery to clinical diagnostics. Infect Genet Evol 2020;79:104211

3 Prati C, Pelliccioni GA, Sambri V, Chersoni S, Gandolfi MG. COVID-19: its impact on dental schools in Italy, clinical problems in endodontic therapy and general considerations. Int Endod J 2020;53(5):723-725

4 The Sociology of Professional Training and Health Manpower: Summary Report. Geneva, Switzerland: World Health Organization, Working Panel on Professional Training; 1972

5 Sharma S, Vijayaraghavan V, Tandon P, Kumar DRV, Sharma H, Rao Y. Dental education: current scenario and future trends. J Contemp Dent Pract 2012;13(1):107-110

6 Kwok YL, Gralton J, McLaws ML. Face touching: a frequent habit that has implications for hand hygiene. Am J Infect Control 2015;43(2):112-114
7 Iyer P, Aziz K, Ojcius DM. Impact of COVID-19 on dental education in the United States. J Dent Educ 2020;84(6):718-722

8 Alshare K, Al-Dwairi M, Akour I. Student instructor perception of computer technologies in developing countries: the case of Jordan. J Comput Inf Syst 2003;43:115-123

9 Jordan J, Jalali A, Clarke S, Dyne P, Spector T, Coates W. Asynchronous vs didactic education: it's too early to throw in the towel on tradition. BMC Med Educ 2013;13:105

10 Xie X, Li Y, Sun H, Liu L. Exhaled droplets due to talking and coughing. J R Soc Interface 2009;6(Suppl 6) :S703-S714

11 Chae JK, Haghdel A, Guadix SW, et al. Letter: COVID-19 impact on the medical student path to neurosurgery. Neurosurgery 2020;87(2):E232-E233

12 Ferrel MN, Ryan JJ. The impact of COVID-19 on medical education. Cureus 2020;12(3):e7492

13 Spinardi AC, Blasca WQ, Wen CL, Maximino LP. Telehealth in speech-language pathology and hearing: science and technology. Pro Fono 2009;21(3):249-254

14 Asiry MA. Dental students' perceptions of an online learning. Saudi Dent J 2017;29(4):167-170

15 Turkyilmaz I, Hariri NH, Jahangiri L. Student's perception of the impact of E-learning on dental education. J Contemp Dent Pract 2019;20(5):616-621

16 Ramos JS, da Silva LK, Pinzan A, Rodrigues A de C, BerretinFelix G. Distance learning: effectiveness of an interdisciplinary course in speech pathology and dentistry. Interdiscip J Elect Skills Life Long Learn 2015;11:101-121

17 Bourzgui F, Alami S, Diouny S. A comparative study of online and face-to-face learning in dental education. EC Dent Sci 2020;19:1-11

18 Piccoli G, Ahmad R, Ives B. Web-based virtual learning environments: a research framework and a preliminary assessment of effectiveness in basic IT skills training. Manage Inf Syst Q 2001;25:401-426

19 Hendricson WD, Anderson E, Andrieu SC, et al. Does faculty development enhance teaching effectiveness? J Dent Educ 2007;71(12):1513-1533 